\title{
Expression of BCL2L12 in acute leukemia patients: Potential association with clinical and prognostic factors
}

Hassan Boustani ${ }^{1}$, Hossein Ayatollahi ${ }^{2}$, Hossein Rahimi ${ }^{3}$, Samaneh Boroumand-Noughabi ${ }^{4}$, Masoumeh Gharib ${ }^{5}$, Mohammad Alidadi ${ }^{6}$, Arezoo Shajiei ${ }^{6}$, Mohammad Hadi Sadeghian ${ }^{2 *}$

1. Department of Lab Sciences, Faculty of Allied Medical Sciences, Ilam University of Medical Sciences, Ilam, Iran

2. Department of Hematology and Blood Bank, Cancer Molecular Pathology Research Center, Faculty of Medicine, Mashhad University of Medical Sciences, Mashhad, Iran

3. Department of Internal Medicine, Faculty of Medicine, Mashhad University of Medical Sciences, Mashhad, Iran

4. Faculty of Medicine, Gonabad University of Medical Sciences, Gonabad, Iran

5. Faculty of Medicine, Mashhad University of Medical Sciences, Mashhad, Iran

6. Cancer Molecular Pathology Research Center, Faculty of Medicine, Mashhad University of Medical Sciences, Mashhad, Iran

*Corresponding author: Tel: +98 5138012584 Fax: +98 5138012584

Address: Department of Hematology and Blood Bank, Cancer Molecular Pathology Research Center, Faculty of Medicine, Mashhad University of Medical Sciences, Mashhad, Iran E-mail: Sadeghianmh@mums.ac.ir

Received; 2015/09/16 revised; 2015/10/27 accepted; 2015/11/16

\section{Abstract}

Introduction: Apoptosis is an important mechanism in both physiological and pathological conditions. The BCL2 family of proteins plays a critical role in regulation of apoptotic cell death. Up and down regulation of BCL2-like 12 (BCL2L12), a new member of the BCL2 family, has been reported in several malignancies. However, the expression level of BCL2L12 rarely has been studied in leukemia. This study was designed to investigate the mRNA expression of BCL2L12 in patients with acute leukemia.

Materials and methods: 90 patients with acute leukemia as case group and 90 healthy persons as controls, were participated this study. RNA was extracted from peripheral blood samples. Expression level of BCL2L12 mRNA was evaluated by a quantitative real-time polymerase chain reaction (qRT-PCR) method and its association with clinical and laboratory findings was analyzed.

Results: The expression of BCL2L12 mRNA was significantly lower in acute lymphoblastic leukemia (ALL) cases comparing the controls $(\mathrm{P}<0.001)$, while it was not significantly different in acute myeloid leukemia (AML) samples compared the control group. In addition, there were higher BCL2L12 level in females (than in males) and in patients with $\mathrm{t}(12 ; 21)$ in ALL patients. There was no association between BCL2L12 expression level and other clinical and laboratory findings of AML patients.

Conclusion: BCL2L12 seems play a role in the pathogenesis of ALL. Further studies with larger sample size is needed to clarify its probable impact on prognosis and therapeutic response.

Keywords: Acute myeloid leukemia, Acute lymphoblastic leukemia (ALL), BCL2L12, Apoptosis

\section{Introduction}

Apoptosis is an important mechanism in physiological conditions, such as embryonic development and tissue homeostasis as well as pathological 
conditions, such as cancer, neurodegenerative conditions and autoimmune diseases (1-3). Aberration in apoptotic pathways is one of the key components in the pathogenesis of lots of malignancies $(1,4)$, including acute and chronic leukemias $(2,5,6)$. In addition dysregulation of normal programmed cell death mechanisms plays an important role in cancer chemoresistance (7-8). The BCL-2 family is one of the most important regulators of apoptosis, containing both anti-apoptotic and pro-apoptotic members $(1,9)$. The pro-apoptotic members of the BCL2 family, including BAX, BAD, BID, and BCLXS, induce apoptosis, whereas the anti-apoptotic members, such as BCL2, BCLXL, and BCLW, suppress the apoptotic machinery (2-4). Over expression of anti-apoptotic members of the Bcl-2 family such as Bcl-2 and Bcl-xL has been implicated in resistance to chemotherapy, whereas over expression of pro-apoptotic proteins such as Bax promotes apoptosis and sensitizes tumor cells to various anticancer drugs (10-13).

The BCL2-like 12 (BCL2L12) protein, a novel member of this family, structurally consists of a highly conserved $\mathrm{BH} 2$ domain, a BH3-like domain, and a prolin rich domain $(5,12)$. BCL2L12 gene is located in 19q13.3 and composed of 7 coding exons and 6 intros which yield to a 334 amino acid long protein (12).To date, the precise function of BCL2L12 gene has not been determined and there are controversial data demonstrating that BCL2L12 involved in both pro- and antiapoptotic mechanisms (14). The BCL2L12 has been studied in several malignancies including chronic lymphocytic leukemia (CLL) (12), glioblastoma (15), nasopharyngeal carcinoma (16), breast cancer (17), and gastric cancer (18, 19). However, BCL2L12 mRNA expression rarely been studied in acute leukemia.

Acute leukemias are a heterogeneous group of hematopoietic malignancies with varying morphologic characteristics (20). Acute lymphoblastic leukemia (ALL) is the most common malignant neoplasm diagnosed in children younger than 15 years, accounting for about $25 \%$ of all cancers and $75 \%$ of all leukemias in this age group. Approximately $80 \%$ of adult onset acute leukemias are acute myeloid leukemia (AML) (21). Based on the 2008 revision of World Health Organization (WHO) classification of acute leukemias, cytogenetic abnormalities are one of the most important criteria for diagnosis and prognosis of acute leukemias (20-22). In addition to cytogenetic abnormalities, several other genetic alterations such as over expression of the anti-apoptotic proteins of the BCL2 family have been proposed as important prognostic factors (23). Konopleva et al. reported that Bcl-2 can be contributed to the survival and chemoresistance of CD34 positive leukemia cells (24). Moreover, a correlation between high $\mathrm{Bcl}-2$ expression and poor response to chemotherapy has been reported in AML (25-27). In addition it has been shown that suppression of Bcl2 expression promotes apoptosis and sensitizes AML cells to chemotherapy (26). In contrast, a relationship between high expression of BCL2 and increased disease-free survival in childhood ALL (29), as well as high BCL2 expression and higher complete remission rates in adults ALL have been reported (30). Moreover, elevated BCL2 expression is a good predictive factor for corticoresistance in $\mathrm{T}$ ALL (31).

As mentioned, data by different studies in various cancers, underlines the role of BCL2L12 in cancer genesis and behavior. However, the role of this protein in acute leukemias is not completely determined yet. There are only few reports about the association between BCL2L12 and AML; and also, to the best of our knowledge, studies about evaluation of BCL2L12 mRNA expression in patients with ALL have not been reported. Regarding these data, BCL2L12 mRNA expression by quantitative real-time polymerase chain reaction (qRT-PCR) method in acute 
leukemia patients was evaluated in this study attempting to find its probable role in the pathogenesis of the disease. Furthermore, the association between BCL2-like12 expression level and other laboratory and clinical findings of patients was analyzed.

\section{Materials and methods}

Study included 90 morphologically confirmed, newly diagnosed acute leukemia patients (45 AML and 45 ALL), who were admitted to Qaem University Hospital, Mashhad, Iran since October 2012 to march 2014. The diagnosis of acute leukemias were made based on the WHO criteria (i.e. more than $20 \%$ blasts in the peripheral blood smear or bone marrow). AML and ALL were differentiated using cytochemistry staining and flow cytometric studies. According to the French-American-British (FAB) criteria, the AML and ALL subtypes were classified morphologically. Patients who had received treatment and samples with low RNA quality were excluded. Ninety age and sex matched healthy individuals were included in the study as controls (45 as AML controls and 45 as ALL controls). The study protocol was approved by the Research Ethics Committee in Mashhad University of Medical Sciences. A written informed consent was obtained from each individual.

Four milliliters of the peripheral blood of the patients and the controls were collected in 2 sterile tubes containing K2-EDTA anticoagulant for RNA extraction and morphologic examination. Demographic characteristics (e.g. age, and gender), clinical data (including splenomegaly, hepatomegaly and lymphadenopathy) and lab data (e.g. complete blood count findings and recurrent genetic abnormalities) were obtained via a questionnaire filled by trained personnel or patients' hospital data.

RNA extraction and cDNA synthesis: The mononuclear blood cells of patients and controls were isolated from their peripheral blood samples using Ficoll gradient centrifugation. Total RNA was extracted by RNX plus ${ }^{\mathrm{TM}}$ kit (Cinnagen, Tehran, Iran) according to the manufacturer's instructions. The quality and quantity of the extracted RNA was evaluated by agarose gel electrophoresis. Total RNA was reversely transcribed using cDNA synthesis kit (thermo scientific, Lithuania).

BCL2L12 expression analysis: The PCR primers for BCL2L12 or Beta-2microglobolin (B2M) were designed (23) as follows: BCL2L12 (gene of interest) forward, 3'- CCCTCGGCCTTGCTCTCT5' and reverse, 3'GGGCCACCAAAGCATAGAAG-5'.

$\mathrm{B} 2 \mathrm{M}$ (housekeeping or reference gene) forward,

3'-CAGCAAG GACTGGTCTTTCTAT-5' and reverse, 3'GCGGCATCTTCAAACCTC-5 .'

Real-time polymerase chain reactions were carried out using thermocycler (Applied Biosystems, Foster City, CA, USA) and SYBR green method by the means of TAKARA Master Mix (Japan). The reaction mixture was prepared by adding $10 \mu \mathrm{l}$ Master Mix, $0.5 \mu 1$ of each primer, 2 $\mu \mathrm{l}$ cDNA, $0.4 \mu \mathrm{l}$ of Rox and $7.1 \mu \mathrm{l}$ of nuclease free water in a total volume of 20 $\mu 1$. The thermal conditions of the study consisted of an initial pre-denuturatun at $95^{\circ} \mathrm{C}$ for $10 \mathrm{~min}$ followed by 40 cycles of denaturation at $95^{\circ} \mathrm{C}$ for 40 seconds, annealing at $60^{\circ} \mathrm{C}$ for 30 seconds, extension at $72^{\circ} \mathrm{C}$ for 30 seconds, and a final extension at $72^{\circ} \mathrm{C}$ for $5 \mathrm{~min}$.

The relative BCL2L12 mRNA expression was calculated using the PCR threshold cycle number (CT) or comparative $\mathrm{Ct}$ $(\Delta \Delta \mathrm{Ct})$ method. The relative fold change in gene expression $=2-\Delta \Delta \mathrm{Ct}$, Where: $\Delta \Delta \mathrm{Ct}=\Delta \mathrm{Ct}$ patients $-\Delta \mathrm{Ct}$ control group and $\Delta \mathrm{Ct}=\mathrm{Ct}$ target gene (BCL2112) $-\mathrm{Ct}$ reference gene (B2M) (42). In this method the amplification efficiencies of the BCL2L12 (Gene of interest) and reference genes must be approximately equal. In our study BCL2L12 and B2M PCR efficiencies were $94.13 \%$ and 98.99 . 


\section{Statistical analysis}

Data management and analysis was performed using SPSS (Statistical software for social analysis-version 11.5). The Kolmogorov-Smirnov test was applied to determine normality of data distribution and then, independent sample t-test and analysis of variance test (ANOVA test) were used for comparing continuous variables (such as levels of BCL2L12 mRNA) between the groups. Chi-Square was used to compare the non continuous variables and Pearson correlation test were used to determine relationship between variables. Differences were considered statistically significant at $\mathrm{P}<0.05$.

\section{Results}

Twenty nine males and 16 females with median age of 43.02 years were participated in the AML group and 26 (57.8\%) male and 19 (42.2\%) female were included in the AML control group with median age of 45.59 years. There were no significant differences between the case and control groups in sex and age $(\mathrm{P}=0.13$ and $\mathrm{P}=0.56$, respectively). The morphologic subtypes of AML consisted of $7 \mathrm{M} 1$ (\%15.6) ,10 M2 (\%22.2), $7 \mathrm{M} 3$ (\%15.6), 12 M4 (\%26.7) and 9 M5 samples. The genetic study revealed $\mathrm{t}(15 ; 17)$ in 7 patients $(\% 15.6), \mathrm{t}(8 ; 21)$ in 2 patient (\%4.4), and inv(16) in 1 patient (\%2.2). The clinical data exhibited splenomegaly in $15 \quad(33.3 \%)$, hepatomegaly in $6(13.3 \%)$ and lymphadenopathy in $1(2.2 \%)$ of patients.

Twenty males (44.4\%) and 25 females $(55.6 \%)$, with a median age of 14.66 years at the time of diagnosis were consisted in the ALL group. In addition, the ALL control group was composed of 22 males (48.9\%) and 23 females (51.1\%), with a median age of 15.34 years. There were no significant differences between the ALL patients and control group in sex and age $(\mathrm{P}=0.26$ and $\mathrm{P}=0.83$, respectively). The morphologic subtypes of ALL consisted of
27 L1 (\%60.0) and 18 L2 (\%40.0) samples. The genetic study demonstrated $\mathrm{t}(12 ; 21)$ in $7(\% 10.3)$ patients, $\mathrm{t}(9 ; 22)$ in 6 (\%8.8) patients, and $\mathrm{t}(1 ; 19)$ in $2(\% 2.9)$ patients. Splenomegaly was seen in 19 (27.9\%), hepatomegaly in $12(17.6 \%)$ and lymphadenopathy in $17(22.1 \%)$ of patients.

The mean \pm standard deviation (SD) level of BCL2L12 mRNA (or BCL2L12 mRNA copies/B2M mRNA copies) was $7.11 \pm$ 2.35 (ranged from 2.91 to 11.01) in the samples of AML patients and $6.15 \pm 1.96$ (ranged from 1.791 to 10.15) in the samples of ALL patients. The mean levels of BCL2L12 mRNA expression in controls of AML and ALL were 7.62 and 7.69, respectively.

The t test showed no significant difference between the AML patients and control group $(\mathrm{P}=0.15)$ in BCL2L12 mRNA expression but the mean level of BCL2L12 mRNA in ALL cases was significantly ( $P$ $<0.001)$ lower than the control group (6.15 vs 7.69$)$.

Tables 1 and 2 show mean level of BCL2L12 expression in different subgroups of patients (based on age, sex, ...). There were not any statistically significant differences between BCL2L12 mRNA expression in different age and sex groups in AML cases and also in age groups in ALL patients. However the mean level of BCL2L12 mRNA in males were significantly $(\mathrm{P}=0.01)$ lower than females (5.2 vs 6.6) in ALL cases.

There were not any significant relationship between BCL2L12 expression and blood hemoglobin $\quad(\mathrm{P}=0.82), \quad \mathrm{RBC} \quad(\mathrm{P}=0.85)$, WBC $(\mathrm{P}=0.78)$, PLT $(\mathrm{P}=0.20)$ in ALL cases and also between BCL2L12 and blood hemoglobin $(\mathrm{P}=0.82), \quad \mathrm{RBC}$ $(\mathrm{P}=0.42)$, WBC $(\mathrm{P}=0.31)$, PLT $(\mathrm{P}=0.89)$ age in ALL patients. Seven patients with $\mathrm{t}(12 ; 21)$ positive in ALL group had significantly $(\mathrm{P}=0.009)$ higher BCL2L12 expression compare to patients without this translocation ( 8.3 vs 5.7 ). 
Table 1. The mean levels of BCL2L12 mRNA expression in different subgroups of the AML patients.

\begin{tabular}{|c|c|c|c|}
\hline & Number(percent) & Mean $B C L 2 L 12$ mRNA expression & P value \\
\hline Sex & & & 0.78 \\
\hline male & 29 & $7.19 \pm 2.27$ & \\
\hline female & 16 & $6.98 \pm 2.56$ & \\
\hline Age (year) & & & 0.16 \\
\hline$<50$ & 28 & $7.51 \pm 2.19$ & \\
\hline$>50$ & 17 & $6.45 \pm 2.51$ & \\
\hline Splenomegaly & & & 0.41 \\
\hline yes & 15 & $6.70 \pm 2.39$ & \\
\hline no & 30 & $7.32 \pm 2.34$ & \\
\hline Hepatomegaly & & & 0.76 \\
\hline yes & 6 & $6.76 \pm 3.13$ & \\
\hline no & 39 & $7.17 \pm 2.25$ & \\
\hline Lymphadenopathy & & & 0.72 \\
\hline yes & 10 & $6.88 \pm 2.32$ & \\
\hline no & 35 & $7.18 \pm 2.39$ & \\
\hline FAB subtype & & & 0.63 \\
\hline M1 & 7 & $5.90 \pm 2.37$ & \\
\hline M2 & 10 & $7.18 \pm 2.49$ & \\
\hline M3 & 7 & $7.79 \pm 2.50$ & \\
\hline M4 & 12 & $7.09 \pm 2.52$ & \\
\hline M5 & 9 & $7.11 \pm 1.96$ & \\
\hline$t(8 ; 21)$ & & & 0.58 \\
\hline yes & 2 & $6.52 \pm 1.17$ & \\
\hline no & 43 & $7.14 \pm 2.39$ & \\
\hline $\mathbf{t}(15 ; 17)$ & & & 0.45 \\
\hline yes & 7 & $7.79 \pm 2.50$ & \\
\hline no & 38 & $6.99 \pm 2.33$ & \\
\hline Inv 16 & & & 0.15 \\
\hline yes & 1 & 10.48 & \\
\hline no & 44 & $7.04 \pm 2.32$ & \\
\hline
\end{tabular}

Table 2. The mean levels of BCL2L12 mRNA expression in different subgroups of the ALL patients.

\begin{tabular}{|c|c|c|c|}
\hline & Total & Mean BCL2L12 mRNA expression & P value \\
\hline Sex & & & 0.01 \\
\hline male & 20 & $5.23 \pm 1.83$ & \\
\hline female & 23 & $6.69 \pm 1.67$ & \\
\hline Age (year) & & & 0.25 \\
\hline$<10$ & 25 & $6.45 \pm 1.84$ & \\
\hline$>10$ & 20 & $5.76 \pm 2.08$ & \\
\hline Splenomegaly & & & 0.12 \\
\hline yes & 19 & $5.56 \pm 1.41$ & \\
\hline no & 26 & $6.51 \pm 2.24$ & \\
\hline Hepatomegaly & & & 0.10 \\
\hline yes & 12 & $5.41 \pm 1.60$ & \\
\hline no & 33 & $6.41 \pm 2.03$ & \\
\hline Lymphadenopathy & & & 0.59 \\
\hline yes & 15 & $6.38 \pm 2.19$ & \\
\hline no & 30 & $6 / 03 \pm 1.87$ & \\
\hline FAB subtype & & & 0.84 \\
\hline L1 & 27 & $6.20 \pm 1.86$ & \\
\hline L2 & 18 & $6.07 \pm 2.16$ & \\
\hline $\mathbf{t}(12 ; 21)$ & & & 0.009 \\
\hline yes & 7 & $8.37 \pm 1.87$ & \\
\hline no & 38 & $5.73 \pm 1.70$ & \\
\hline $\mathbf{t}(\mathbf{9} ; 22)$ & & & 0.85 \\
\hline yes & 6 & $6.23 \pm 0.92$ & \\
\hline no & 39 & $6.13 \pm 2.08$ & \\
\hline$t(1 ; 19)$ & & & 0.60 \\
\hline yes & 2 & $6.65 \pm 1.03$ & \\
\hline no & 43 & $6.12 \pm 2.00$ & \\
\hline
\end{tabular}




\section{Discussion}

BCL2-like-12 gene (BCL2L12) cloned by Scorilas et al. in 2000; is a newly identified member of the BCL2 family. Up- and down- regulated BCL2L12 expression levels have been reported in various malignancies $(13,16,34)$. To the best of our knowledge, importance and prognostic impact of BCL2L12 in acute leukemias have not been completely clarified yet.

This study was done on 90 patients with de novo acute leukemia and 90 healthy controls. We detected significantly lower levels of BCL2L12 mRNA in ALL samples versus control samples $(\mathrm{p}=0.001)$. In addition the BCL2L12 mRNA expression level was lower in AML group than the controls (7.11 vs. 7.62$)$ but the differences were not statistically significant. In line to our study Thomadaki et al. examined the expression of this gene in 21 patients with de novo AML and did not find significant differences $(\mathrm{p}=0.14)$ between case and control groups (5.75 vs. 14.82) (35). In contrast to our results, $\mathrm{Yu}$ et al. reported a significantly $(\mathrm{P}<0.01)$ lower level of BCL2L12 gene expression in 134 AML patients compared to control group (36). Although BCL2L12 expression in our AML patients was lower than control group (7.11 vs. 7.62) but the differences were not statistically significant. Lower BCL2L12 mRNA expression has been reported in other malignancies such as breast cancer (37) and higher BCL2L12 mRNA levels have been detected in CLL $(15,40)$, Nasopharyngeal carcinoma (16), bladder carcinoma (34). The dissimilarity between relative BCL2L12 expression in our study comparing the other studies (such as Thomadaki et al study) may be the result of using different reference genes; While we used B2M, they employed GAPDH as internal control (reference) gene.

We did not find any article concerning relations between the levels of BCL2L12 mRNA with acute lymphoblastic leukemia. Similar study was done on relations between the levels of Bcl-2 with acute leukemia (29-31). In the ALL group, we found a higher BCL2L12 level in females (than in males) and in patients with $\mathrm{t}(12 ; 21)$. In addition we did not find any association between BCL2L12 expression level and any of the clinical and laboratory findings of AML patients. In a similar study, Thomadaki et al. did not find any relationship between BCL2L12 expression level and hepatomegaly $(\mathrm{P}=0.23), \mathrm{FAB}$ classification $(\mathrm{P}=0.31)$ and hemorrhagic syndrome $(\mathrm{P}=0.44)$ however they demonstrated an association between BCL2L12 expression level and splenomegaly $(\mathrm{P}=0.04)(35)$.

The impact of other BCL2L12 family proteins, such as BCL2 has been investigated in AML, too. It has been demonstrated that BCL2 expression was associated with hyperleukocytosis and also M4 and M5 subtypes of AML (31, 40). Higher mean BCL-2 expression in newly diagnosed AML patients (M1, M2 FAB subtypes) compared to controls has been reported by El-Shakankiry et al. using western blotting (40).

Interestingly, it has been suggested recently that BCL2L12 may be used as a new biomarker in specific types of cancers (16). Furthermore, it has been demonstrated that BCL2L12 over expressed breast cancer patients are less likely to develop relapse or die in comparison to down regulated patients (17). In nasopharyngeal carcinoma the high BCL2L12 expression level was associated with more aggressive forms of the disease (18). In contrast with CLL and nasopharyngeal carcinoma, BCL2L12 expression in gastric and breast cancers was correlated with favorable prognosis (18-19).

Although it has shown that BCL2L12 interacts with the p53 tumor suppressor, but the functional role of BCL2L12 protein not completely clarified. The study 
by Steghet et al. demonstrated that BCL2L12 inhibits binding of P53 to promoter elements of its target genes. Additionally they reported that BCL2L12 reduces p53 protein stability in response to DNA damage (15). Regarding the function of BCL2L12 in apoptosis, BCL2L12 may play a role in pathogenesis of malignancies such as acute leukemias.

Conclusion: This study showed that expression of BCL2L12 mRNA was significantly lower in ALL comparing the controls, while it was not significantly different in AML samples comparing the control group. Our finding suggested that BCL2L12 may play an important role in pathogenesis of ALL but it seems that

\section{References}

1. Dewson G, Kluck RM. Bcl-2 familyregulated apoptosis in health and disease. Cell Health Cytoskeleton. 2010; 2(1):9-22.

2. Kontos CK, Christodoulou MI, Scorilas A. Apoptosis-related BCL2Family Members: Key Players in Chemotherapy. Antican Agent Med Chem. 2013; 2(1):123-9.

3. Borner $\mathrm{C}$. The Bcl-2 protein family: sensors and checkpoints for life-ordeath decisions. Mol Immunol. 2003; 39(11):615-47.

4. Kirkin V, Joos S, Zörnig M. The role of Bcl-2 family members in tumorigenesis. Biochimica et Biophysica Acta. 2004; 1644(2):22949.

5. Tzifi F, Economopoulou C, Gourgiotis $\mathrm{D}$, Ardavanis A, Papageorgiou S, Scorilas A. The role of BCL2 family of apoptosis regulator proteins in acute and chronic leukemias. Advanc Hematol. 2011; 4(1):342-8.

6. Ackler S, Mitten MJ, Foster $\mathrm{K}$, Oleksijew A, Refici M, Tahir SK, et al. The Bcl-2 inhibitor ABT-263 enhances the response of multiple chemotherapeutic regimens in hematologic tumors in vivo. Cancer
BCL2L12 do not contribute in the pathogenesis of AML. Further studies with larger sample sizes as well as follow up of the patients is needed to clarify the exact role of BCL2L12 in the tumor genesis of acute leukemias and its probable effect on prognosis and resistance to therapy.

\section{Acknowledgement}

This paper is the result of the Msc thesis of Mr. Hassan Boostani which is supported by deputy of research, Mashhad University of Medical Sciences. We also would like to thank all of the patients for participating in this study.

Chemother Pharmacol. 2010; 66(5):869-80.

7. Kang MH, Reynolds CP. Bcl-2 inhibitors: targeting mitochondrial apoptotic pathways in cancer therapy. Clin Cancer Res. 2009; 15(4):112632.

8. Yip K, Reed J. Bcl-2 family proteins and cancer. Oncogene. 2008;27(50):6398-406.

9. Deng X, Kornblau SM, Ruvolo PP, May WS. Regulation of $\mathrm{Bcl} 2$ phosphorylation and potential significance for leukemic cell chemoresistance. JNCI Monographs.2000; 2000(28):30-7.

10. Chauhan D, Velankar M, Brahmandam M, Hideshima T, Podar K, Richardson $\mathrm{P}$, et al. A novel Bcl-2/Bcl-XL/Bcl-w inhibitor ABT-737 as therapy in multiple myeloma. Oncogene. 2007;26(16):2374-80.

11. Frenzel A, Grespi F, Chmelewskij W, Villunger A. Bcl2 family proteins in carcinogenesis and the treatment of cancer. Apoptosis. 2009;14(4):584-96.

12. Flora $T$, Christina E, Dimitrios G, Alexandros A, Sotirios P, Andreas S. The role of bcl2 family of apoptosis regulator proteins in acute and chronic 
leukemias. Adv Hematol. 2012; 2012: 524308.

13. Papageorgiou SG, Kontos CK, Pappa V, Thomadaki H, Kontsioti F, Dervenoulas $J$, et al. The novel member of the BCL2 gene family, BCL2L12, is substantially elevated in chronic lymphocytic leukemia patients, supporting its value as a significant biomarker. Oncologist. 2011; 16(9):1280-91.

14. Nakajima A, Nishimura K, Nakaima Y, Oh T, Noguchi S, Taniguchi T, et al. Cell type-dependent proapoptotic role of BCL2L12 revealed by a mutation concomitant with the disruption of the juxtaposed Irf3 gene. Proc Nation Acad Sci. 2009;106(30):12448-52.

15. Stegh AH, Kim H, Bachoo RM, Forloney KL, Zhang J, Schulze H, et al. Bcl2L12 inhibits postmitochondrial apoptosis signaling in glioblastoma. Gene Develop. 2007;21(1):98-111.

16. Fendri A, Kontos CK, Khabir A, Mokdad-Gargouri R, Scorilas A. BCL2L12 is a novel biomarker for the prediction of short-term relapse in nasopharyngeal carcinoma. Mol Med. 2011;17(3-4):163.

17. Thomadaki H, Talieri M, Scorilas A. Prognostic value of the apoptosis related genes BCL2 and BCL2L12 in breast cancer. Cancer Lett. 2007;247(1):48-55.

18. Korbakis D, Scorilas A. Quantitative expression analysis of the apoptosisrelated genes BCL2, BAX and BCL2L12 in gastric adenocarcinoma cells following treatment with the anticancer drugs cisplatin, etoposide and taxol. Tumor Biol. 2012;33(3):865-75.

19. Florou D, Papadopoulos IN, Scorilas A. Molecular analysis and prognostic impact of the novel apoptotic gene BCL2L12 in gastric cancer. Biochem Biophys Res Communicat. 2010; 391(1):214-8.
20. Vardiman JW, Thiele J, Arber DA, Brunning RD, Borowitz MJ, Porwit A, et al. The 2008 revision of the World Health Organization (WHO) classification of myeloid neoplasms and acute leukemia: rationale and important changes. Blood. 2009;114(5):937-51 .

21. Pui CH. Acute lymphoid leukemia. In: Kaushansky K, Lichtman MA, Kipps TJ, Seligsohn U, Prchal PT, editors. Williams Hematology. 8th ed. New York: McGraw-Hill; 2010: P.14091411.

22. Grimwade D, Hills RK, Moorman AV, Walker H, Chatters S, Goldstone AH, et al. Refinement of cytogenetic classification in acute myeloid leukemia: determination of prognostic significance of rare recurring chromosomal abnormalities among 5876 younger adult patients treated in the United Kingdom Medical Research Council trials. Blood. 2010;116(3):354-65.

23. Rockova V, Abbas S, Wouters BJ, Erpelinck CA, Beverloo HB, Delwel $\mathrm{R}$, et al. Risk stratification of intermediate-risk acute myeloid leukemia: integrative analysis of a multitude of gene mutation and gene expression markers. Blood. 2011;118(4):1069-76.

24. Konopleva M, Zhao S, Hu W, Jiang S, Snell V, Weidner D, et al. The antiapoptotic genes $\mathrm{Bcl}-\mathrm{X}(\mathrm{L})$ and $\mathrm{Bcl}-2$ are over-expressed and contribute to chemoresistance of non-proliferating leukaemic CD34 ${ }^{+}$cells. Br J Haematol. $2002 ; 118(2): 521-34$.

25. Campos L, Rouault J-P, Sabido O, Oriol P, Roubi N, Vasselon C, et al. High expression of bcl-2 protein in acute myeloid leukemia cells is associated with poor response to chemotherapy. Blood. 1993;81(11):3091-6.

26. Reed JC. Bcl-2-family proteins and hematologic malignancies: history and 
future prospects. Blood. 2008;111(7):3322-30.

27. Parker JE, Mufti GJ, Rasool F, Mijovic A, Devereux S, Pagliuca A. The role of apoptosis, proliferation, and the $\mathrm{Bcl}-2-$ related proteins in the myelodysplastic syndromes and acute myeloid leukemia secondary to MDS. Blood. 2000;96(12):3932-8.

28. Milella M, Estrov Z, Kornblau SM, Carter BZ, Konopleva M, Tari A, et al. Synergistic induction of apoptosis by simultaneous disruption of the Bcl-2 and MEK/MAPK pathways in acute myelogenous leukemia. Blood. 2002;99(9):3461-4.

29. Coustan-Smith E, Kitanaka A, Pui C$\mathrm{H}$, McNinch L, Evans WE, Raimondi $\mathrm{SC}$, et al. Clinical relevance of BCL-2 overexpression in childhood acute lymphoblastic leukemia. Blood. 1996;87(3):1140-6.

30. Del Principe MI, Del Poeta G, Maurillo L, Buccisano F, Venditti A, Tamburini A, et al. P-glycoprotein and BCL-2 levels predict outcome in adult acute lymphoblastic leukaemia. Br $\mathrm{J}$ Haematol. 2003;121(5):730-8.

31. Baghdassarian N, Bertrand Y, Ffrench P, Duhaut P, Bryon P, Ffrench M. Role of BCL-2 and cell cycle regulatory proteins for corticosensitivity assessment in childhood acute lymphoblastic leukaemia. $\mathrm{Br} \quad \mathrm{J}$ Haematol. 2000;109(1):109-16.

32. Livak KJ, Schmittgen TD. Analysis of relative gene expression data using real-time quantitative PCR and the 2(Delta Delta $\mathrm{C}(\mathrm{T}))$ Method. Methods. 2001; 25:402-408.

33. Scorilas A, Kyriakopoulou L, Yousef GM, Ashworth LK, Kwamie A, Diamandis EP. Molecular cloning, physical mapping, and expression analysis of a novel gene, BCL2L12, encoding a proline-richprotein with a highly conserved $\mathrm{BH} 2$ domain of the
Bcl-2 family. Genomics. 2001; 72(2):217-21.

34. Foutadakis S, Avgeris $M$, Tokas $T$, Stravodimos K, Scorilas A. Increased BCL2L12 expression predicts the short-term relapse of patients with TaT1 bladder cancer following transurethral resection of bladder tumors. Urol Oncol. 2014;32(1):e2936 .

35. Thomadaki H, Floros KV, Pavlovic S, Tosic N, Gourgiotis D, Colovic M, et al. Overexpression of the novel member of the BCL2 gene family, BCL2L12, is associated with the disease outcome in patients with acute myeloid leukemia. Clin Biochem. 2012;45(16-17):1362-7.

36. Yu MX, Lu Y, Mu QT, Wang Q, Chen ZM, Lou JY, Jin J. Expression of BCL2L12 gene in de novo acute myeloid leukemia and its clinical implications. Zhonghua Yi Xue Yi Chuan Xue Za Zhi. 2013;30(5):544-8.

37. Tzovaras A, Kladi-Skandali A, Michaelidou K, Zografos GC3, Missitzis I, Ardavanis A, Scorilas A.BCL2L12: a promising molecular prognostic biomarker in breast cancer. Clin Biochem. 2014;47(18):257-62.

38. Karan-Djurasevic T, Palibrk V, Zukic B, Spasovski V, Glumac I, Colovic M, Colovic N, Jurisic V, Scorilas A, Pavlovic S, Tosic N.Expression of Bcl2L12 in chronic lymphocytic leukemia patients: association with clinical and molecular prognostic markers. Med Oncol. 2013;30(1):405 .

39. Sahu G, Jena RK.Clinical significance of P53 and Bcl-2 in acute myeloid leukemia patients of Eastern India. Hematol Rep. 2011;3(3):e28.

40. El-Shakankiry NH, El-Sayed GM, ElMaghraby S, Moneer MM. Bcl-2 protein expression in egyptian acute myeloid leukemia. J Egypt Natl Canc Inst. 2009;21(1):71-6. 